\title{
Coupled Microstructural and Calorimetric Investigation of Controlled Solder Joint Microstructures in Pb-Free Solders
}

\author{
I.E. Anderson,* A.J. Boesenberg, ${ }^{* *}$ D.C. Riegner,** and J.L. Harringa* \\ *Division of Materials Sciences and Engineering, Ames Laboratory (USDOE), Iowa State \\ University, Ames, IA 50011 \\ **Materials Science and Engineering Department, Iowa State University, Ames, IA 50011
}

Due to increased environmental regulations and market forces, the international electronic assembly industry is seeking a versatile replacement for $\mathrm{Pb}$-containing solders. Pb-free solder alloys based on $\mathrm{Sn}-\mathrm{Ag}-\mathrm{Cu}$ (SAC) ternary eutectic have promise for widespread adoption, but some assembly and operating environments present reliability issues [1]. Persistent undercooling control (reduction) seems critical for generating SAC solder joints with a preferred solidification path and microstructure (with significant fine eutectic fraction), since wide variations of cooling rate, substrate composition, and joint volume are encountered in different electronic assembly processes [2]. Such control over the joint solidification process can help Pb-free SAC solders achieve the consistency of the previous $\mathrm{Sn}-\mathrm{Pb}$ eutectic or near-eutectic solders at generating a uniform reliable microstructure with well-distributed phases that approach the impact tolerance of $\mathrm{Sn}-\mathrm{Pb}$, but with greater resistance to high temperature strength degradation and creep.

An improved near-eutectic SAC composition, Sn-3.5Ag-0.95Cu (wt.\%), was designed [3] to exert enhanced thermodynamic driving force for a preferred pro-eutectic phase, $\mathrm{Cu}_{6} \mathrm{Sn}_{5}$, instead of $\mathrm{Ag}_{3} \mathrm{Sn}$ (found to reduce as-soldered impact strength), while maintaining a narrow melting range, ! $\mathrm{T}(\mathrm{L}+\mathrm{S})=3^{\circ} \mathrm{C}$, with close proximity to the eutectic to enhance the possible eutectic phase fraction. This improved SAC composition (termed SAC3595) can be compared to the more common SAC305 and SAC105 with only $0.5 \% \mathrm{Cu}$ that use a decreased Ag content of $3.0 \%$ and $1.0 \%$, respectively, that were designed to reduce driving force for pro-eutectic $\mathrm{Ag}_{3} \mathrm{Sn}$ formation [2]. However, impact test results of SAC305 and SAC105 showed that minor quaternary additions, e.g., $\mathrm{Mn}$ and $\mathrm{Ti}$, still were needed to achieve consistent impact resistance [4], presumably because of occasional joint solidification products (probably $\mathrm{Ag}_{3} \mathrm{Sn}$ ) that embrittled the unmodified SAC alloys. Thus, an extensive investigation of the improved SAC3595 alloy was conducted [5] with a more comprehensive set of $4^{\text {th }}$ element additions that were designed to substitute for $\mathrm{Cu}$ in the $\mathrm{Cu}_{6} \mathrm{Sn}_{5}$ (pro-eutectic and interfacial) phase, both to promote initial nucleation of the $\mathrm{Cu}_{6} \mathrm{Sn}_{5}$ and to enhance subsequent nucleation of -Sn and the ternary eutectic. The set of additives was selected by a Darken-Gurry analysis [5] that indicated relative potential for substitutional alloying into $\mathrm{Cu}$ and included $\mathrm{Fe}, \mathrm{Ni}$, and $\mathrm{Co}$, with slightly smaller atoms, and $\mathrm{Zn}$, Mn (more common valence), and Al, with slightly larger atoms, as shown in Fig.1. Since these nucleant additions were assumed to require less average undercooling and probably less variation in undercooling than SAC3595, differential scanning calorimetry (DSC) was chosen to monitor the joint solidification process of the experimental alloys. In fact, due to the availability of $\mathrm{Cu}$ sample pans and lids for the DSC, model solder joints were made by melting and freezing of each solder alloy foil in a fluxed $\mathrm{Cu}$ sample container [5]. After solidification, these model solder joints were sectioned and metallographically prepared for microstructural analysis by SEM, electron microprobe analysis (EPMA), and nano-hardness indention experiments. 
Undercooling measurements, summarized in Fig. 2, and microstructural analysis results revealed that the most preferred additions were $\mathrm{Al}, \mathrm{Zn}, \mathrm{Mn}$, but the $\mathrm{Zn}$ additive appeared to be the only one that behaved according to the designed approach, according to the available experimental evidence. An example of the solder joint microstructure that was catalyzed by a minor $\mathrm{Zn}$ addition is given in Fig. 3, but results for the others also will be presented. Some initial evidence with the $\mathrm{Zn}$ additive also indicates that the modified SAC3595 alloys can also achieve thermal cycling $\left(-55 /+125^{\circ} \mathrm{C}\right)$ lifetimes for BGA joints that qualify for avionics electronics products.

\section{References:}

[1] K.N. Tu, A.M. Gusak, and M. Li, J. Appl. Phys. 93 (3), p. 1335 (2003).

[2] S.K. Kang, P.A. Lauro, D.-Y. Shih, D.W. Henderson, and K.J. Puttlitz, IBM J. Res. \& Dev., 49 (4/5), p. 607 (2005).

[3] I.E. Anderson, J Mater Sci: Electron, 18 (55), p. 76 (2007).

[4] W. Liu and N-C. Lee, JOM, 59 (7), p. 26 (2007).

[5] I.E. Anderson, J.W. Walleser, J.L. Harringa, F. Laabs, A. Kracher, JEM, 38 (12), p.2770 (2009).

[6] Support from Iowa State University Research Foundation and Nihon-Superior, Inc., through Ames Lab contract no. DE-AC02-07CH11358 is gratefully acknowledged.

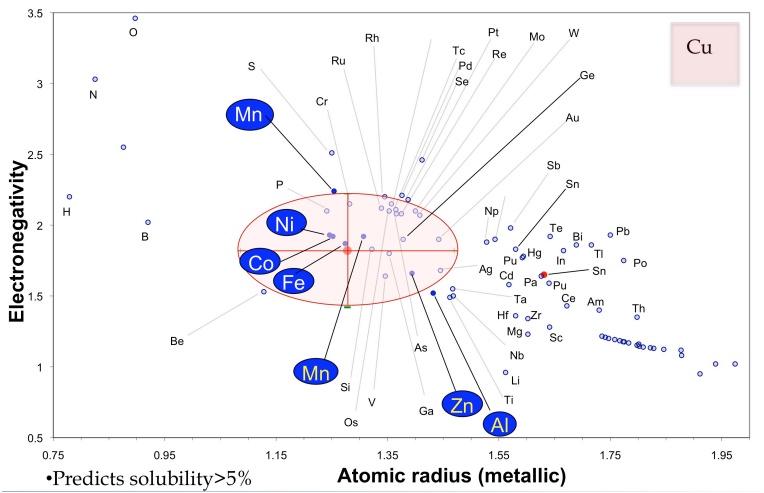

Figure 1. Darken-Gurry ellipse analysis.

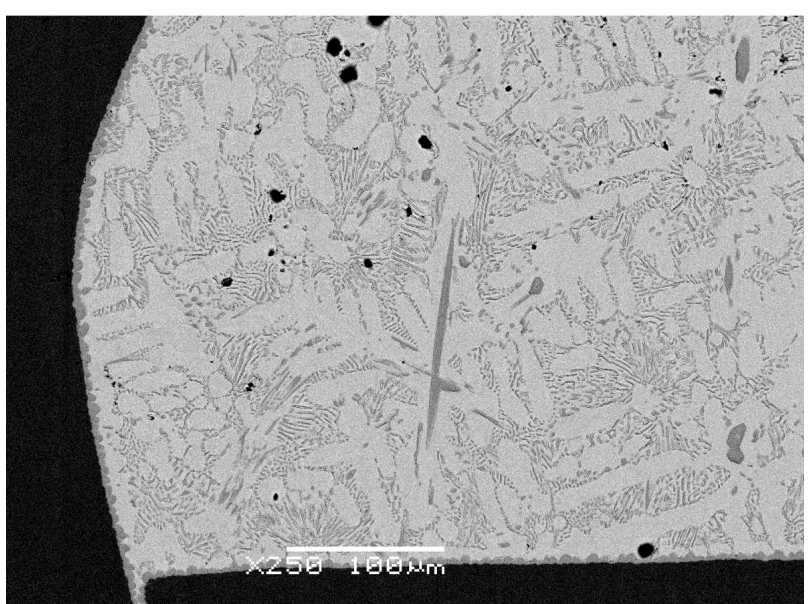

a.

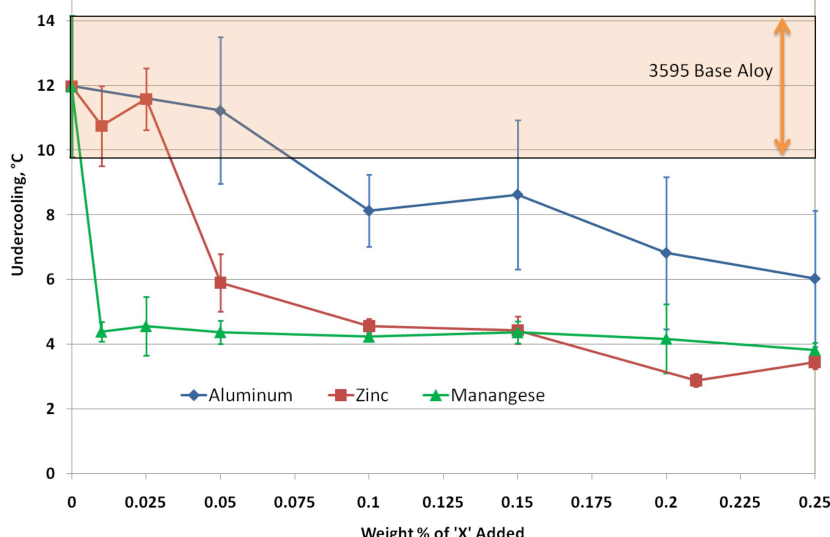

Figure 2. Summary of undercooling results.



b.

Figure 3. SEM micrographs of a solder joint made from Sn-3.5Ag-0.74Cu-0.21Zn (wt.\%). 